\title{
Commentary
}

\section{A comment on Thomas Saaty's proposed International Center for Conflict Resolution}

\author{
C. Theodore LARSON \\ Professor Emeritus of Architecture, University of Michigan, Ann \\ Arbor, U.S.A.
}

The name of the proposed organization is its most questionable aspect. To me, the term 'center' denotes a set of physical facilities and an organization of people capable of performing certain activities (towards goals and objectives) within a space-restricted geographic location, the selection of which could provoke much confusion and unnecessary argument, as Saaty himself points out. What he advocates is really the creation of an international network that will constitute a complex global system of component subsystems (each a national center unlimited in space and time), all completely decentralized, amorphous and elastic, but interlocking and interacting, and capable of dealing with problems of human systems management and development at different magnitudes of geographic importance and relevance - personal, local, regional, national, continental, global (on land, underwater, or in the air) and including even the extraterrestrial.

Thanks to the phenomenal advances that are being made in computer science and technology and in electronic telecommunication and teleconferencing (both audio and visual), network planning and design on an infinitely variable worldwide scale has now become possible. Unhappily,
Saaty does not have too much to say about this emerging resource for the cultural development of people. More amplifying detail could, and should, be developed by the author and commentators.

Establishment of an International Network for Conflict Resolution is a necessary prelude to the creation of a Worldwide Intelligence System for the Development of Omniscience in Mankind (WISDOM), as suggested in "The changing urban patterns of a global society" (HSM 1 (1) (1980) 39-46). Without 'peace' (the prevention of war through an evolving technique of conflict resolution worldwide), there can be no really fruitful improvement of either human kind or Planet Earth.

After all, what could be a more obscene form of human insanity than the spectacle of sovereign nations, big and little, striving to outdo one another in the development and use of weapons designed to destroy human life to the greatest extent conceivable?

Man's acquired knowledge of nuclear energy has already made war a totally obsolete as well as utterly immoral concept of conflict resolution. But peace cannot be achieved as just a negation of armed conflict between nations. The proposed international network for $\mathrm{CR}$ would also have to formulate and promote a coordinated program of $\mathrm{R} \& \mathrm{D}$ aimed at obtaining a progressive improvement in living conditions for everyone in every community on this planet.

North-Holland Publishing Company

Human Systems Management 3 (1982) 323

0167-2533/82/0000-0000/\$02.75 ㄷ 1982 North-Holland 